\title{
Deconvolution of design parameters from elasto- plastic energy data acquired by nanoindentation in ceramic coatings
}

\author{
Obtención de parámetros de diseño para capas cerámicas a partir de mediciones de \\ energía elasto-plástica adquirida por nanoindentación
}

\author{
Juan Carlos Castrillón Trujillo' ${ }^{1}$ Juan Manuel Meza Meza² \\ ${ }^{a}$ Profesor Universidad EAFIT, Estudiante de doctorado, Facutlad de Minas, Universiad Nacional de Colombia, Medellín, \\ Colombia. \\ jccastrillont@unal.edu. co \\ ${ }^{b}$ Universidad Nacional de Colombia, sede Medellín, Laboratorio de Tribología y Superficies - GTS, Calle 75 No 79 A -5, \\ Bloque M17, Medellín, Antioquia, Colombia, 050034 \\ jmmezameunal .edu.co
}

\begin{abstract}
Resumen - Las energía elasto-plásticas y el parámetro RID (Relative Indentation Depth: cociente entre la máxima profundidad de indentación y el espesor del recubrimiento, $\beta=$ $h_{\max } / t$ ) se utilizaron para evaluar la capacidad de soportar carga de materiales con recubrimientos cerámicos. El estudio se realizó en sistemas sustrato-recubrimiento de TiN con espesores de $2 \mu \mathrm{m}$ y $3 \mu \mathrm{m}$ depositados por PAPVD sobre acero M2 y sobre acero inoxidable 304L. Se analizaron gráficos de dureza $v s . \beta$ y $W p / W t$ vs. $\beta$. Se encontraron correlaciones para diferentes profundidades de indentación a las que se da la transición entre la respuesta mecánica del recubrimiento y la respuesta mecánica del sistema sustrato-recubrimiento; y en los puntos donde la eficiencia de usar el recubrimiento cae al 33 y al 50\%. Se demostró que puede obtenerse información importante a partir de los datos de energía sobre la respuesta mecánica de un sistema sustrato-recubrimiento, sin necesidad de recurrid al método de Oliver y Pharr para medir la dureza y el módulo de elasticidad.
\end{abstract}

Palabras clave- Energía de indentación, profundidad de indentación relativa (RID), recubrimientos duros.

Abstract - The elasto-plastic energies and the RID parameter (Relative Indentation Depth $\beta=h_{\max } / t$ ), defined as the ratio between the maximum indentation depth and the coating thickness, were used to evaluate the ability of the ceramic coated systems to withstand load. The study was conducted on M2 and 304L steels coated with titanium nitride by PAPVD. Both substrates were coated with TiN of about 2,0 and $3,0 \mu \mathrm{m}$ thickness. The hardness vs. $(\beta)$ and the ratio of plastic to total energy $(W p / W t)$ vs. $(\beta)$ graphs were analyzed. There were found correlations between the indentation depths at which the transition from mechanical response due to the coating to the mechanical response of substrate-coating and to substrate dominated behavior and the depths at which the efficiency of using the coating falls $33 \%$ and $50 \%$. Results show that it is possible to get useful information from the energy taken from the mechanical response of the coated systems to avoid the
Oliver and Pharr method for measuring the hardness and elastic modulus.

Keywords - Energy indentation, relative indentation depth (RID), hard coatings, ceramic coatings.

\section{INTRODUCTION}

In reference [1], based on Tuck et al. [2][3] work, it was found that the graphics of load and hardness as function of $R I D$ and load as function of depth $\left(h^{\eta}\right)$, provide important information regarding the ability of the systems TiN-M2 and TiN-304L to withstand load.

For the reason that in bulk materials there is a relationship between the elasto-plastic properties and contact energies [4], reference [1] suggests using these elasto-plastic data to build curves RID and explore whether this type of graphs provides some useful information. That is why this article is intended to address this problem and verify if it is possible or not to correlate the energy with parameters associated with the mechanical response of the systems aforementioned. Due to the relevence of the RID parameter [2], and the concept of elasto-plastic contact energy, they will be summarized below.

\section{A. RID curves (Tuck's model)}

Tuck et al. [2], proposed a model to evaluate the hardness of a coated systems based on RID plots; this model, based on (1), also provides information to predict the mechanical behavior of the coated system.

$$
\frac{H_{c}-H_{s}}{H_{f}-H_{s}}=\frac{1}{1+\left(\frac{\beta}{\beta_{0}}\right)^{X^{*}}}
$$


The parameters $\beta_{o}$ and $\chi$, are associated with the system's ability to bear load. $H_{c}, H_{s}$, and $H_{f}$ are the hardness of the composite, the substrate, and the coating, respectively. $\beta_{o}$ is an efficiency parameter which is interpreted as the ratio of indentation depth to the coating thickness at which the improvement in hardness of the coated system (due to the ceramic coating presence) increases by 50\%. $\chi$ is a parameter which shows how drastic is the change between the hardness of the coating and substrate and it is related to the mode of coating fracture failure (see Fig. 1). A RID plot including $\beta_{o}$ along with the $\beta_{2 / 3}$ parameter (related to a $66 \%$ of efficiency) is illustrated in Fig. 1.

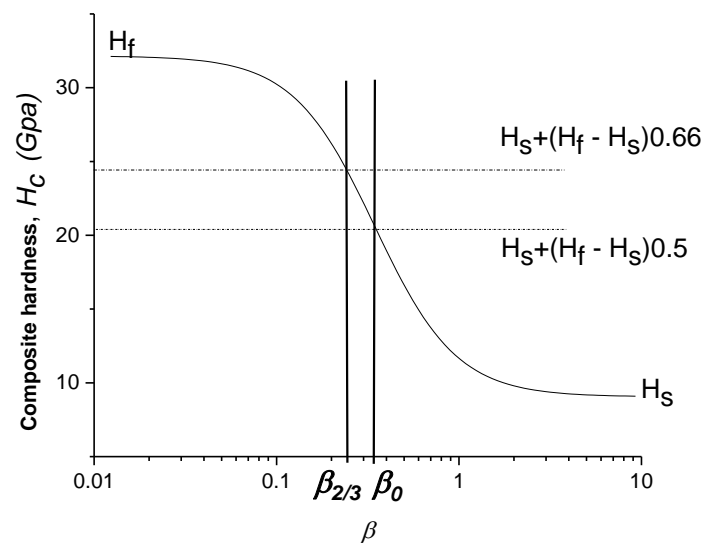

Figure 1. Schematic representation of a RID plot illustrating the behavior of $H c$, composite hardness, as a function of relative indentation depth $\beta$. The graph also shows two of the design parameters $\beta_{2 / 3}$ and $\beta_{0}$ as defined by Tuck et al. [2].

\section{B. Elasto-plastic energy and mechanical behavior by instrumented indentation testing.}

Fig. 2 shows a load-displacement curve generated by instrumented indentation test where the main parameters as maximum depth $\left(h_{m}\right)$, final depth $\left(h_{f}\right)$ and maximum load $\left(P_{m}\right)$ are indicated. From this plot it is possible to extract the elastic energy $\left(W_{e}\right)$, the plastic Energy $\left(W_{p}\right)$ an the total energy $\left(W_{T}=W_{p}+W_{e}\right)$ shown in the figure as hatched areas.

Loading and unloading curves are well described by power law functions $P=\kappa h^{2}$ and $P=\left(h_{m}-h_{f}\right)^{n}$ respectively. Where $\kappa$ depends on the material properties and indenter geometry; $b$ and $n$ are considered as numerical set of parameters. A full revision of Tuck's models and mechanical contact energies can be found in references [25].

Based on the definition that hardness is a measure of the resistance to plastic deformation (irreversible deformation) and, taking into account that the plastic energy is a measure of the irreversible energy associated to the indentation process, it can be concluded that the energy measurements can be correlated with the hardness as it has been demonstrated by [5].

Using these arguments we are going to construct RID plots, based on energy measurements, and propose some parameters that will be demonstrated and related to those obtained from RID plots based on hardness.

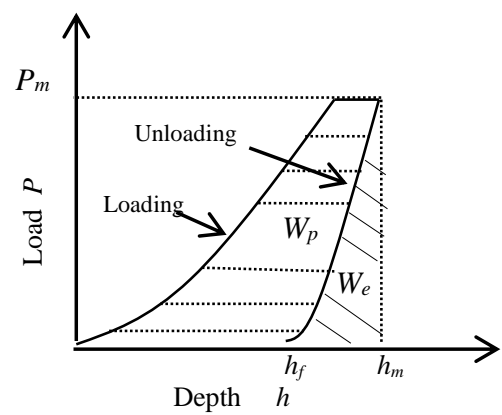

Figure 2. Schematic representation of the loading-unloading curve representing a nanoindentation test. Hatched areas correspond to plastic $(W p)$ and elastic energy $(W e)$. (See other parameter in the text).

Following the lines afore stated, we propose to construct $R I D$ plots based on energy, particularly using the ratio $W p / W t$, because it will represent the ratio of the irreversible energy (related with the hardness) to the total expended energy. So, from $W p / W t$ vs. $\beta$ curves (see Fig 4 ) the $R I D$ values for which the ratio $W p / W t$ equals to half, $(W p / W t)_{m}$, and one-third, $(W p / W t)_{d}$, of its total value were calculated These $R I D$ values were defined as $\beta_{m}$ y $\beta_{d}$ respectively. These two RID values, will be demonstrated can be related to those proposed by Tuck based on hardness-RID plots, namely $\beta_{o}$ y $\beta_{2 / 3}$.

\section{EXPERIMENTAL STUDY}

\section{A. Materials and methods}

Cylindrical M2 tool steel samples were heat treated to a hardness of about $59 \mathrm{HRC}$, while 304L stainless steel were left as received state; both materials were metallographically polished and cleaned before coated [6]. The titanium nitride coatings were deposited in a Balzers commercial reactor using a PAPVD arc system. More details on materials, coatings and equipment used for characterization are found in reference [1].

The nano-indentation test was carried out in a Fisher H100V equipment; a Vickers indenter with an area function previously calibrated was used [7]. To obtain the hardness and elastic modulus, the data was post-processed according to the Oliver and Pharr method [8]. Using this data, graphs of Fig. 3 and 4 were constructed; and the data adjusted to the function (2). 


$$
Y=y_{0}+\left(\frac{2 A}{\pi}\right)\left[\frac{\omega}{4\left(\beta-x_{c}\right)^{2}+\omega^{2}}\right] .
$$

In Fig. 3, $Y$, (in (2)), corresponds to hardness of the system, $H$, whereas, in Fig. 4, $Y$ corresponds the ratio $W p / W t$. Full lines in this figures represents the predictions of the function, which produces correlation factors (CF) above 98 $\%$ for all samples except for $M 2(3,0 \mu \mathrm{m})$ which produces a $\mathrm{CF}$ of $93 \%$. It is important to clarify that the fitting curves discard the data at low penetrations, because these data are highly influenced by the tip indenter roundness.

Following the work done by Tuck, $\beta_{o}$ and $\beta_{2 / 3}$ values were calculated using equation (2) to adjust the $H$ vs. $\beta$ data (Fig 3 ). In addition, from the top plateau shown in these curves, a region where the coating hardness shows its maximum value and then starts to decrease has been chosen in order to define a criteria to stablish where the coating begins to be influenced by mechanical response of substrate. The criterion defined for this transition was to select a spot on the fitting curve, in which the coating's hardness begin to change in a noticeable way. It was found that this change starts when the slope in the flat top part of the curve is about $22 \%$, which corresponds to an angle of $-20^{\circ}$, respect to the point of zero slope. So, at the top of $H c$ vs. $\beta$ curves, these $\beta$ values were defined as $\beta_{T}$. Similarly, from points of zero
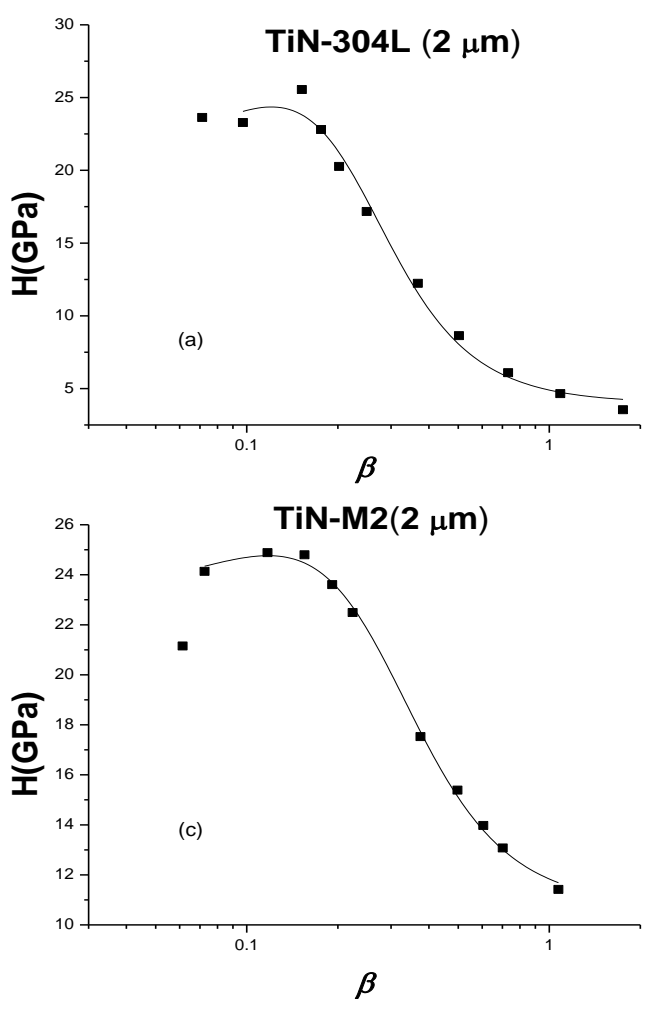

slope, at the lowest plateau in $W_{p} / W_{t}$ vs. $\beta$ curves, the transition point was defined as $\beta_{w}$.

\section{RESULTS AND DISCUSSION}

Fig. 3 shows the hardness as function of the relative indentation depth. At low depths the hardness increases with load and this is because the tip of the indenter is considerably blunt (the tip radius was estimated about 1.2 $\mu \mathrm{m})$. According to Hertz equations for elastic contact, the mean contact pressure depends on the cube of the contact radius, so as the load is increased, the mean contact pressure increases until the spherical portion of the tip is left and the pyramidal part rules the indentation phenomenon, eventually a full plastic flow regime is developed. This is shown as a plateau, at the top of these plots, which corresponds to the coating's hardness value with no influence of the substrate. Then, the hardness starts to be influenced by the substrate; the literature reports that this occurs at about $R I D=0.1$ (for hard coatings deposited onto soft substrates) [9]. Finally, the hardness of the substrate rules the behavior. The $\beta_{T}$ values reported in table 1 , are close to the expected RID value of 0.1 [9], which suggest that the criteria adopted in present work can be more objective than the simple rule of thumb of $10 \%$ of thickness $(R I D=0.1)$
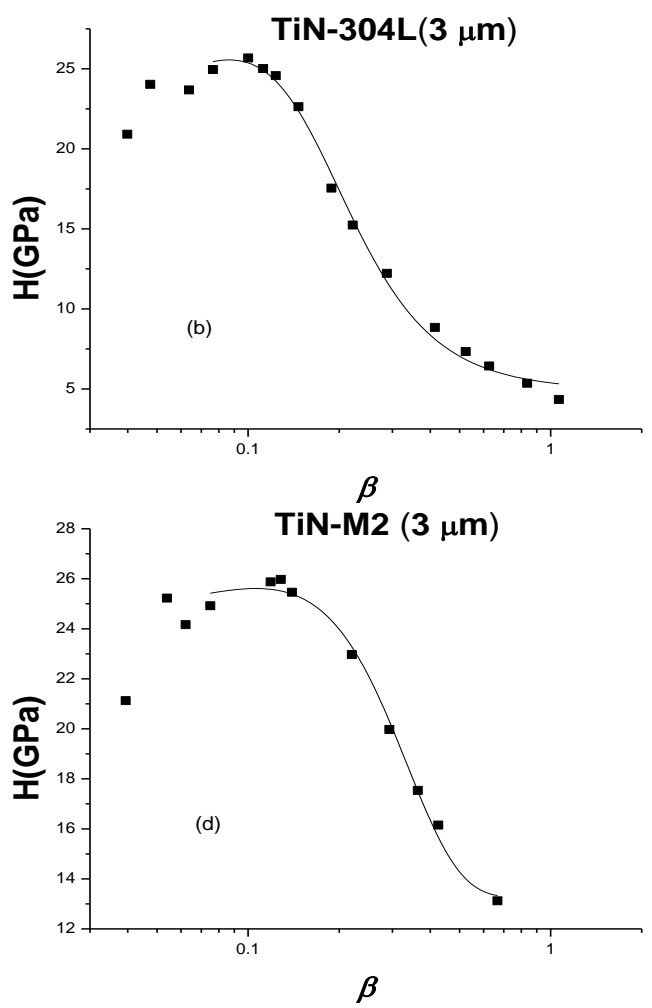

Figure. 3. Change in hardness (measured by Oliver and Pharr) depending on the relative indentation depth of the four systems considered in this study: TiN-304L $(2.0 \mu \mathrm{m})$, TiN-304L $(3.0 \mu \mathrm{m})$, TiN-M2 $(2.0 \mu \mathrm{m})$ and TiN-M2 $(3.0 \mu \mathrm{m})$. 
$R I D$ plots based on the $W p / W t$ ratios are shown in Fig. 4. Clearly, there is a slope change at the bottom of these plots, that change occurs in a zone where substrate starts to influence the mechanical behavior of the system, that transition is defined by the point $\beta_{W}$, whose values are shown in Table 1.

Table 1. Presents values of $\beta$ obtained from the graphs $H$ vs. $\beta$ and $W p / W t$ vs. $\beta$, which correspond to points where the slope decrease or increases about $22 \%$, those points are defined as $\beta_{T}$ and $\beta_{W}$ respectively; also values of $W p / W t$ and hardness at these points are shown.

\begin{tabular}{ccccc}
\hline $\begin{array}{c}\text { Substrate } \\
\text { (thickness) }\end{array}$ & $\beta_{T}$ & $\beta_{W}$ & $(W p / W t)_{W}$ & $H_{W}(G P a)$ \\
\hline $\begin{array}{c}304 \mathrm{~L} \\
(2 \mu \mathrm{m})\end{array}$ & 0.12 & 0,10 & 0.35 & 24.12 \\
\hline $304 \mathrm{~L}$ & 0.08 & 0,08 & 0.38 & 25.51 \\
$(3 \mu \mathrm{m})$ & & & & \\
\hline $\mathrm{M} 2$ & 0.12 & 0.06 & 0.33 & 24.10 \\
$(2 \mu \mathrm{m})$ & & & & \\
\hline $\mathrm{M} 2$ & 0.11 & 0,12 & 0.42 & 25.57 \\
$(3 \mu \mathrm{m})$ & & & & \\
\hline
\end{tabular}

More interestingly, $\beta_{W}$ values (based on energy plots) are close to $\beta_{T}$ values (from hardness plots) which suggest that the curves of energy vs. RID, can already be used to determine the transition in the mechanical response, due only to the coating, to a response where the substrate starts to influence the mechanical behavior of the system.

On the other hand, Fig 4 shows energy-based-RID plots. From these plots, the RID values at which the plastic energy is half of the total energy $(W p / W t)_{m}$ and two thirds of the total energy $(W p / W t)_{d}$ were calculated; these $R I D$ values are $\beta_{\mathrm{m}}$ y $\beta_{\mathrm{d}}$ respectively. Table 2 shows $\beta_{\mathrm{m}}$ y $\beta_{\mathrm{d}}$ along with $\beta_{\mathrm{o}}$ and $\beta_{2 / 3}$ values defined by Tuck et al. [2], as well as the hardness and $(W p / W t)$ values associated with each one of the different $R I D$ values above.

Comparing the values of $\beta_{\mathrm{m}}$ with $\beta_{\mathrm{o}}$, and $\beta_{2 / 3}$ with $\beta_{\mathrm{d}}$, presented in Table 2 , it is evident that the values of $\beta$, based on hardness-RID plots, have the same trends as the values of $\beta$ defined in present paper, based on energy RID plots. In both cases, the respective depths at which efficiency of using the coating is $50 \%$ and $66.6 \%$, are similar to the depths to which a half and a third of the plastic energy indentation has been dissipated. The differences, in principle, are due to the hardness definition itself, even though hardness is related to the plastic energy, the correlation is not direct.
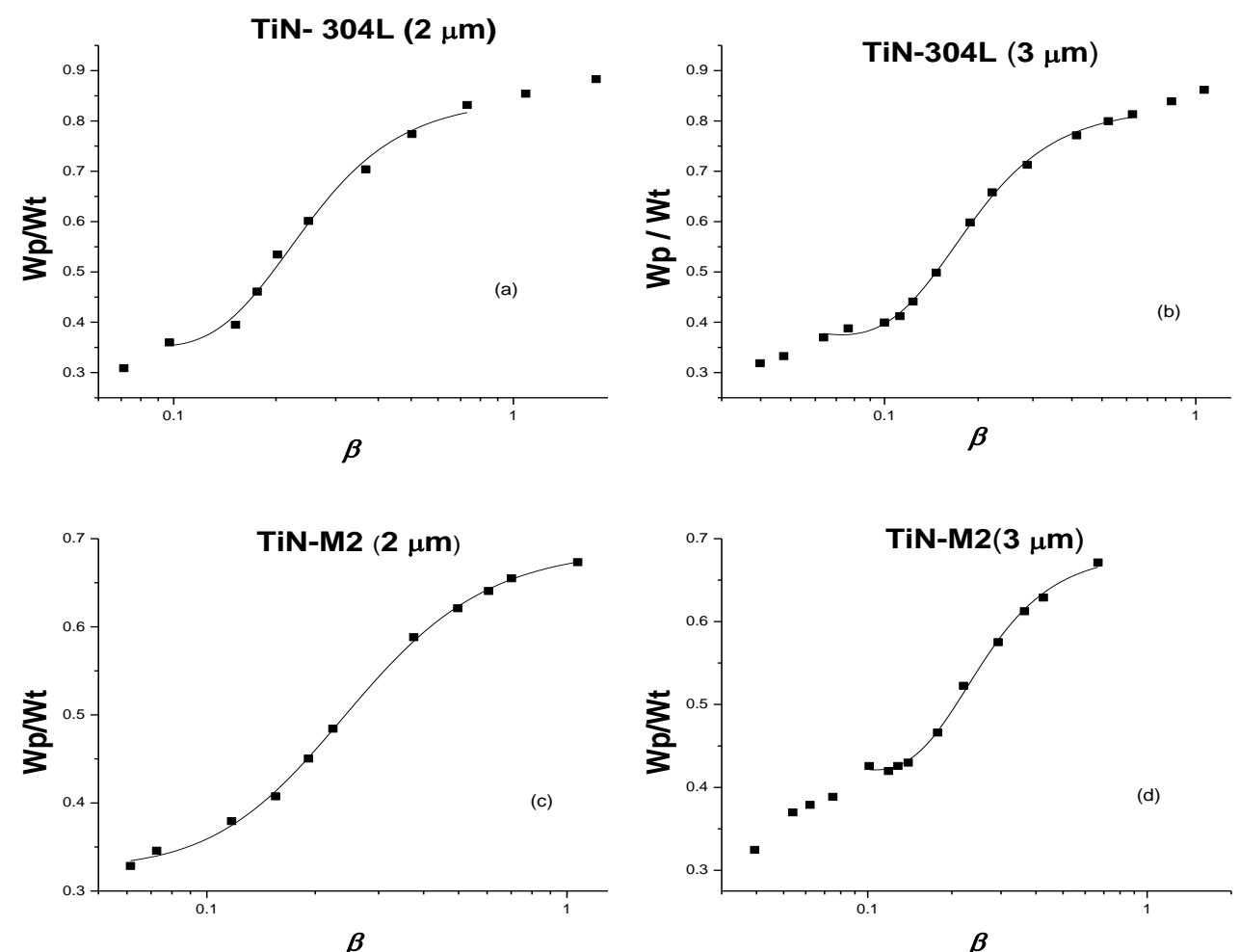

Figure 4. Graphic performance of $W p / W t$ depending on parameter $\beta$, for 4 coating systems: a) TiN-304L (2.0 $\mu \mathrm{m})$, b) TiN-304L (3.0 $\mu \mathrm{m})$, c) TiN-M2 (2.0 $\mu \mathrm{m})$ and d) TiN-M2 $(3.0 \mu \mathrm{m})$.

On the other hand, the tip's roundness of the indenter could play an important role in the plastic to elastic ratio. Moreover, the Oliver and Pharr method used to extract the hardness is also dependent on the indenter area function, which can lead to some bias in the properties. 
Table 2, also shows the values of $\left(W_{p} / W_{t}\right)$ at $\beta_{m}$ and $\beta_{d}$ and, the values of $H$ at $\beta_{m}, \beta_{d}, \beta_{o}$ and $\beta_{2 / 3}$. It may be noticed that, although the amounts $H_{m}$ and $H_{o}$, and, $H_{d}$ and $H_{2 / 3}$, are not equal (as stated before), the trends are maintained in their respective values.

Generally, in this kind of materials, there are plenty of phenomena concerning hardness response and not only mechanical deformation, cracks, densification, etc. all these phenomena are captured by the energy values measured by the indentation test whilst unloading curves that are used to measure hardness and elastic modulus, do not always capture the phenomena described above. Despite differences between both approximations, it is clear that a correlation exists among them and is more direct by the energy approximation, and probably more meaningful, because it does not depends on the calibration of an area function. However, a wide range of coated materials must be evaluated to probe the robustness of the proposed method; currently we are developing such study.
On the other hand, it is clear that on top of $H$ vs. $\beta$ curves in Fig. 3, where the depth of indentaction is very low, hardness values are very similar, no matter the substrate onto which the coat was deposited. This is because it is the same coating in all cases, regardless of the thickness and the material of substrate.

It is also apparent that the relative depth, at which the coating efficiency drops to $50 \%$ or $33.3 \%$, is bigger for the coating systems with lower thicknesses. This is ruled by the residual stresses state which in turns depends on microestructure, processing temperature gradient and thickness. For example on TiN coatings, it have been reported tensile residual stresses for this size of thickness and that they increase with the thickness [10]. However other authors have reported a compressive residual stress state [11].

Table 2. Values of relative indentation depth, corresponding values of $W p / W t$ and hardness $(H)$, calculated by the method of Tuck et al. [3] are presented. Similarly, values for which the efficiency of using a coating is decreased by one-third and 50\% defined in this work are shown.

\begin{tabular}{|c|c|c|c|c|c|c|c|c|c|c|c|}
\hline Susbstrate & Thickness & $(W p / W t)_{m}$ & $\beta_{m}$ & $H_{m}$ & $(W p / W t)_{d}$ & $\beta_{d}$ & $H_{d}$ & $\beta_{o}$ & $\beta_{2 / 3}$ & $H_{o}$ & $H_{2 / 3}$ \\
\hline \multirow[b]{2}{*}{$304 \mathrm{~L}$} & $2.0 \mu \mathrm{m}$ & 0.61 & 0.27 & 16,80 & 0.52 & 0.21 & 20.64 & 0,32 & 0,26 & 13.6 & 17.1 \\
\hline & $3.0 \mu \mathrm{m}$ & 0.60 & 0.20 & 17,70 & 0.52 & 0.16 & 21,50 & 0,22 & 0,17 & 15.7 & 20.03 \\
\hline \multirow[b]{2}{*}{ M2 } & $2.0 \mu \mathrm{m}$ & 0.50 & 0.25 & 21.90 & 0.45 & 0.19 & 23,80 & 0,37 & 0.30 & 17.56 & 19.83 \\
\hline & $3.0 \mu \mathrm{m}$ & 0.54 & 0.25 & 21.11 & 0.50 & 0.21 & 23.65 & 0,32 & 0.27 & 19.10 & 21.3 \\
\hline
\end{tabular}

\section{CONCLUSIONS}

Energy based RID plots allow to propose some parameters to measure the response of ceramic coating systems. Those parameters follow the same trends of those ones proposed by Tuck et al. [3], based on Hardness-RID plots. The great advantage of the proposed parameters is that they do not depend on the area function, which is necessary to obtain the hardness (Oliver and Pharr method), furthermore, they are accessed directly from the P-h plots which in turn are subjected to lower uncertainties. However, deeper studies with a variety of samples must be conducted to probe the generality of the method.

\section{ACKNOWLEDGEMENTS}

The authors acknowledge the support of this research to The Materials Characterization Laboratory of The Department of Materials and Minerals, Mines School, National University of Colombia-Medellín, and to "the National Program Call Supporting Graduate Students to Strengthen Research, Creation and Innovation at the National University of Colombia" for economic stimulus of one of the researchers (Quipu code 200000013169).

\section{REFERENCES}

[1] J.M. Meza., A. Devia, and J.M. Vélez. "The importance of RID and $P V s . h^{n}$ curves on indentation studies of TiN films deposited onto M2 and 304L steel, Rev. la Fac. Ing., "No. 37, pp. 93-106, 2006.

[2] J.R. Tuck, A.M. Korsunsky, S.J. Bull, and R.I. Davidson, "On the application of the work-ofindentation approach to depth-sensing indentation experiments in coated systems, Surf. Coatings Technol., vol. 137, No. 2-3, pp. 217-224,. 2001.

[3] J.R. Tuck, S.J. Korsunsky, D.G. Bath, and R.I. Davidson, R.I, "Indentation hardness evaluation of cathodic arc deposited thin hard coatings", Surf. Coatings Techno., vol. 139, No. 1, pp. 63-74, 2001.

[4] G. de With, and J. Malzbender, "Energy dissipation , fracture toughness and the indentation load displacement curve of coated materials", Surface and Coatings Technology, 135 (2000) 60-68.

[5] Yang-Tse Cheng, Che-Min Cheng, "Relation between hardness, elastic modulus and the work of indentation", Applied Physics Letters, vol. 73, No.5, 1998. 
[6] J.M. Meza, "Modelación del ensayo de nanoindentación para la medición de propiedades mecánicas", M.S Tesis, Universidad Pontificia Bolivariana, Medellín, Colombia, 2008.

[7] J. M. Meza, M.C.M. Farias, R.M. Souza, and J, Cruz. "Using the ratio: maximum load over unload stiffness squared, $\mathrm{P}_{\mathrm{m}} / \mathrm{S}_{\mathrm{u}}{ }^{2}$, on the evaluation of machine stiffness and area function of blunt indenters on depth-sensing indentation equipment", Mat. Res. vol. 10, no. 4, pp. 437-447, 2007.

[8] W.C. Oliver, G.M. Pharr, "An improve technique for determining hardness and elastic modulus using load and displacement sensing indentation experiments", Journal of Materials Research, vol. 7, No. 6, 1992.
[9] S. Zheng, Y. Sun, and T. Bell, "Finit element analysyis of the critical ratio of coatings thickness to indentation depth for coating propertiy measurements by nanoindetation", Thin Solid Films, vol. 258, no. 1-2, pp. 198, 1995.

[10] A.A. Volinsky, L. Zhang, H. Yang, and X. Pang, "Microstructure, residual stress, and fracture of sputtered TiN Films",Surface and Coatings Technology, vol. 224, pp. 120-125, 2013.

[11] M. Monsalve, E. López, J.M. Meza, and F. Vargas, "Estudio mediante difracción de rayos $\mathrm{x}$ de las tensiones residuales producidas durante el deposito de películas delgadas de TiN sobre sustratos metálicos", Rev. Fac. Ing. Antioquia, No. 54, pp. 32-41, 2010. 